\title{
PARTICIPAÇÃO NOS LUCROS E RESULTADOS: Desafios e Benefícios Sob e Perspectiva da Teoria da Agência ${ }^{1}$
}

\author{
PROFIT SHARING AND RESULTS: Challenges and Benefits under the Perspective of \\ the Agency's Theory
}

\section{PARTICIPACIÓN EN LOS BENEFICIOS Y RESULTADOS: Desafíos y Beneficios bajo y Perspectiva de la Teoría de la Agencia}

\author{
Paulo Henrique Amaral Rody, Mestrando em Ciências Contábeis pela FUCAPE \\ Business School. Endereço Profissional: FaSerra - Instituto de Ensino Superior Blauro \\ Cardoso de Mattos. Rua L, nº 11, Rosário de Fátima, 29161152 - Serra, ES - Brasil. Telefone: \\ (27) 33183078. Homepage: www.faserra.edu.br. E-mail: paulohrody@gmail.com.
}

Nilmara Oliveira da Luz, Especialista em Gestão Tributária e Sucessória pela FUCAPE Business School. Endereço Profissional: Fundação Instituto Capixaba de Pesquisas em Contabilidade, Economia e Finanças (Fucape Business School). Av. Fernando Ferrari, 1358 Boa Vista, 29075505 - Vitória, ES - Brasil. Telefone: (27) 40094444. Homepage: www.fucape.br. E-mail: nillmara@ hotmail.com.

Luiz Claudio Louzada, Doutor em Administração pela Universidade Federal de Minas Gerais. Endereço Profissional: Universidade Federal do Espírito Santo, Centro de Ciências Jurídicas e Econômicas. Av. Fernando Ferrari, 514, Goiabeiras, 29075910 - Vitória, ES - Brasil. Telefone: (27) 40092602. Fax: (27) 40092756. Homepage: http://www.ccje.ufes.br/dcc. E-mail: louzaldalvi@yahoo.com.br.

\begin{abstract}
RESUMO
A teoria da agência prevê que as empresas ao oferecerem incentivos financeiros aos funcionários, tendem a alcançar o alinhamento de interesses entre principal e agente. Dentro desse contexto, objetivou-se neste artigo verificar os desafios e benefícios de um programa de participação nos lucros e resultados de uma Siderúrgica localizada no Estado do Espírito Santo. Trata-se de uma pesquisa descritiva com abordagem qualitativa dos dados. Estes que foram coletados por meio de pesquisa de campo e estudo de caso, realizados em uma Siderúrgica situada no Estado do Espírito Santo, por meio de pesquisa documental do Plano de Participação nos Lucros e Resultados (PPLR) e de entrevista semiestruturada com a Analista de Remuneração dessa Siderúrgica. Os resultados sugerem que as metas que compõem o PPLR devem ser claras e objetivas, no sentido de serem compreensíveis e alcançáveis pelos empregados da empresa; e que a distribuição dos recursos gerados pela unidade empresarial entre seus funcionários exerce influência no desempenho desses funcionários, fazendo com que eles trabalhem de forma mais eficiente, tornando possível alinhar os interesses entre principal e agente. Entende-se que este artigo contribuiu para a ampliação do entendimento do fenômeno estudado, ao levantar informações sobre adoção de um PPLR, evidenciando os desafios,
\end{abstract}

\footnotetext{
${ }^{1}$ Artigo submetido em 11/01/2018, revisado em 15/02/2018, aceito em 22/02/2018 e divulgado em 10/07/2018 pelo Editor João Carlos Hipólito Bernardes do Nascimento, após double blind review.
}

GєCont, v. 5, n. 1, Floriano-PI, Jan-Jun. 2018. 
benefícios, estrutura e principais características; e ao confirmar a premissa levantada pela teoria da agência de que, a concessão de incentivos ou gratificações a funcionários de uma organização, permite que uma empresa consiga alinhar os interesses entre principal e agente.

Palavras-chave: Conflitos de Agência; Participação nos Lucros e Resultados.

\section{ABSTRACT}

The agency theory predicts that companies by offering financial incentives to employees, tend to achieve alignment of interest between principal and agent. In this context, the aim of this article verify the challenges and benefits of profit sharing of Steel in the state of Espirito Santo. It is a descriptive research with qualitative approach. These were collected through field research and case study, performed in a Steel located in the state of Espirito Santo, through documentary research Participation Plan Profit Sharing (PPLR) and semi-structured interviews with Analyst this remuneration Steel. The results suggest that the goals that make up the PPLR should be clear and objective, to be understandable and attainable by employees of the company; and that the distribution of funds generated by the business unit among its employees has influence in any way the performance of these employees, making them work more efficiently, making it possible to align the interests between principal and agent. It is understood that this article has helped to expand the understanding of the phenomenon studied, to gather information on adopting a PPLR, highlighting the challenges, benefits, structure and main characteristics; and to confirm the premise raised by agency theory that the granting of incentives or bonuses to employees of an organization, allows a company can align the interests between principal and agent.

Keywords: Agency conflicts; Participation in profit sharing.

\section{RESUMEN}

La teoría de la agencia prevé que las empresas al ofrecer incentivos financieros a los empleados, tienden a alcanzar la alineación de intereses entre el principal y el agente. Dentro de ese contexto, se objetivó en este artículo verificar los desafíos y beneficios de un programa de participación en los beneficios y resultados de una Siderúrgica ubicada en el Estado de Espírito Santo. Se trata de una investigación descriptiva con enfoque cualitativo de los datos. Los que fueron recolectados por medio de investigación de campo y estudio de caso, realizados en una Siderúrgica situada en el Estado de Espírito Santo, por medio de una investigación documental del Plan de Participación en los Beneficios y Resultados (PPLR) y de entrevista semiestructurada con la Analista Remuneración de esta Siderúrgica. Los resultados sugieren que las metas que componen el PPLR deben ser claras y objetivas, en el sentido de ser comprensibles y alcanzables por los empleados de la empresa; y que la distribución de los recursos generados por la unidad empresarial entre sus empleados influye de alguna manera en el desempeño de estos funcionarios, haciendo que ellos trabajen de forma más eficiente, haciendo posible alinear los intereses entre el principal y el agente. Se entiende que este artículo contribuyó a la ampliación del entendimiento del fenómeno estudiado, al levantar informaciones sobre la adopción de un PPLR, evidenciando los desafios, beneficios, estructura y principales características; y al confirmar la premisa planteada por la teoría de la agencia de que la concesión de incentivos o gratificaciones a funcionarios de una organización permite que una empresa pueda alinear los intereses entre el principal y el agente.

Palabras clave: Conflictos de Agencia; Participación en los Beneficios y Resultados.

\section{INTRODUÇÃO}

GєCont, v. 5, n. 1, Floriano-PI, Jan-Jun. 2018. 
$\mathrm{O}$ $\mathrm{s}$ incentivos financeiros podem afetar positivamente o comportamento dos funcionários de uma firma fazendo com que os interesses entre estes e os dos proprietários fiquem alinhados (BAKER; JENSEN; MURPHY, 1988; BAILEY; BROW; COCCO, 1998; BECHT; BOLTON; RÖELL, 2002). Entre os principais incentivos financeiros figura a Participação nos Lucros e Resultados (PLR) que é um mecanismo de gestão que pode ser capaz de aperfeiçoar a performance de uma firma por meio da redução da assimetria informacional, como destacam Drobetz, Schillhofer e Zimmermann (2003), Baek, Kang e Park (2004) e Bernardino, Peixoto e Ferreira (2015) os mecanismos de gestão impactam no desempenho da empresa, por meio da redução da assimetria de informações, uma vez que os gerentes possuem elevado número de informações sobre o desempenho de seus funcionários. Nesse sentido, para Louzada, Silva Junior e Rody (2013) a PLR é uma ferramenta capaz de contribuir com um melhor desempenho dos funcionários de uma empresa, minimizando dessa forma, os conflitos de interesses entre principal e agente.

A teoria da agência é uma das vertentes da teoria contratual da firma, as abordagens da teoria da firma remontam a 1932, com Berle e Means, com a obra intitulada "The Modern Corporation and Private Property", obra que discute o problema de desalinhamento de interesses entre o proprietário da firma e seus gerentes e demais funcionários. Ao admitir que os indivíduos inseridos numa empresa, buscam a satisfação pessoal de seus interesses, pode-se concluir que os interesses entre principal e agente são diferentes e opostos (BERLE; MEANS, 1932).

Conforme Aquino et al. (2007) a teoria da agência enfatiza a importância da existência de uma relação harmônica e equilibrada entre os indivíduos de uma firma, de modo que seus interesses estejam alinhados em prol de um objetivo em comum. A teoria da agência menciona a importância dos incentivos e do interesse individual no ambiente organizacional, concentrando-se na busca de mecanismos capazes de elevar o desempenho organizacional (FELTHAM; XIE, 1994; COOREIA; AMARAL, 2006).

Dentro do contexto da teoria da agência, a contabilidade exerce importante papel, fornecendo informações úteis nesse processo de tomada de decisão, que auxiliam na resolução dos conflitos de agência, contribuindo com o alinhamento de interesses entre principal e agente (ELDENBURG; WOLCOTT, 2007; PIRES, 2008).

Nesse sentido, uma forma de minimizar os conflitos de agência, alinhando os interesses entre principal e agente é através da Participação nos Lucros e Resultados (PLR), que conforme Becker (1998), compreende uma estrutura moderna de remuneração que cria incentivos para que os funcionários participem efetivamente do negócio, podendo ser capaz de alinhar os interesses entre principal e agente. Diversas pesquisas evidenciaram a contribuição que a PLR pode promover em uma empresa, por meio da redução dos conflitos de agência, como a pesquisa de Maia (2003) que destacou que a PLR torna possível alinhar os interesses entre os indivíduos de uma firma.

Dentro desse cenário, com a existência de conflitos de interesses entre os indivíduos envolvidos no ambiente organizacional, faz-se necessário investigar os mecanismos de gestão capazes de alinhar os interesses entre principal e agente. Desse modo, formulou-se o seguinte problema de pesquisa: Quais são os desafios e benefícios de um programa de participação nos lucros e resultados de uma Siderúrgica localizada no Estado do Espírito Santo?

Desse modo, diante do atual problema de pesquisa, este artigo possui três objetivos, listados a seguir, nesta ordem, o primeiro, objetivo geral e os demais, objetivos específicos: 1) Identificar os desafios e benefícios de um programa de participação nos lucros e resultados de uma Siderúrgica localizada no Estado do Espírito Santo; 2) Verificar quais são as características de um programa de participação nos lucros e resultados implementado em uma Siderúrgica localizada no Estado do Espírito Santo; e 3) Analisar sob o ponto de vista da Analista de 
Remuneração de uma Siderúrgica, quais os principais desafios e benefícios de um programa de participação nos lucros e resultados.

Desse modo, para atingir os objetivos desta pesquisa, os dados foram coletados através de pesquisa documental e entrevista semiestruturada em uma Siderúrgica, situada no Estado do Espírito Santo que utiliza a Participação nos Lucros e Resultados, para distribuir parte dos resultados alcançados entre seus funcionários.

Conforme as premissas da teoria da agência que prevê que as empresas, ao oferecerem incentivos financeiros aos agentes, tendem a alcançar o alinhamento de interesses entre principal e agente. Nesse sentido, é importante investigar os mecanismos capazes de reduzir os conflitos de interesses entre os indivíduos de uma organização. Por isso, a relevância deste artigo está em levantar informações sobre adoção de um PPLR evidenciando os desafios, benefícios, estrutura e principais características; e em evidenciar a possibilidade de minimizar os conflitos de interesses em um ambiente empresarial, alinhando os interesses entre principal e agente através da adoção de um Programa Participação nos Lucros e Resultados.

As próximas partes da pesquisa foram organizadas desta forma: (2) Referencial Teórico: foram abordados os assuntos pertinentes relacionados ao tema deste artigo, utilizando como referências autores de livros, artigos e dissertações; (3) Metodologia: foi evidenciado como os dados da pesquisa foram coletados e analisados, bem como os demais aspectos relevantes relacionados à metodologia da pesquisa; (4) Descrição e Análise dos Resultados: pesquisa documental e entrevista semiestruturada realizadas em uma Siderúrgica localizada no Estado do Espírito Santo, que utiliza a Participação nos Lucros e Resultados (PLR) entre seus funcionários. (5) Considerações Finais: avaliaram-se as respostas obtidas através da coleta e análise dos dados confrontando-as com o problema de pesquisa e com os objetivos da pesquisa; apresentaram-se as contribuições para a ampliação do fenômeno estudado; comentam-se as limitações da pesquisa e recomendações para futuras pesquisas.

\section{REFERENCIAL TEÓRICO}

\subsection{TEORIA DA AGÊNCIA: ASPECTOS TEÓRICOS}

Para Jensen e Meckling (1976) no contexto da teoria da agência uma ou mais pessoas (Principal) emprega uma outra pessoa (Agente) para executar em seu nome um serviço que implique a delegação de algum poder de decisão ao agente. Os conflitos de agência surgem quando ambas as partes envolvidas na relação de agência buscam a maximização de seus próprios interesses, desse modo há boas razões para acreditar que o agente nem sempre agirá de acordo com os interesses do principal (ROSS, 1973; JENSEN; MECKLING, 1976; LAMBERT, 2001). Tal teoria é pautada na segregação entre propriedade e controle no ambiente organizacional, como abordado nas pesquisas de (FAMA; JENSEN, 1983; JENSEN, 1986; JENSEN, 1994; BEBCHUK; WEISBACH, 2010).

Segundo Gheller (2001), Fochesatto (2002), Bonner e Sprinkle (2002) e Maia (2003) a PLR é uma importante peça de apoio às práticas relacionadas à geração de estímulos para obter maior comprometimento da equipe de trabalho, podendo reduzir os conflitos de agência. Para Becker (1998) o programa de remuneração variável pode possibilitar para uma empresa, uma estrutura moderna de remuneração e criar incentivos para que o funcionário participe efetivamente do negócio, buscando uma relação menos conflituosa entre empresa e trabalhadores através de formas de motivação mais objetivas para o funcionário.

Segundo Goyal e Park (2002), Besanko et al. (2006) e Devers et al. (2007) na ausência de algum mecanismo que possa alinhar os interesses do principal e do agente, o agente fica propenso a não se importar com o valor gerado para a empresa. É nesse contexto que figuram 
os custos de agência que apesar de serem onerosos para a entidade, tem como principal objetivo tentar solucionar ou minimizar um conflito de agência existente entre principal e agente.

É importante ressaltar que mesmo após alinhar os interesses entre agente e principal, este deverá arcar com gastos de monitoramento, para que assim possa continuar obtendo as informações acerca do comportamento do agente, dada a assimetria informacional que possivelmente continuará existindo mesmo com a sintonia de interesses entre principal e agente. Nesse sentido, Paulino (2010) evidenciou que determinada empresa por meio de seu controle interno conseguiu minimizar a ocorrência de conflitos de agência (riscos de oportunismo e assimetria de informações), garantindo o cumprimento do contrato de parceria e a satisfação com o negócio.

De acordo com Eldenburg e Wolcott (2007) diversas organizações utilizam informações contábeis para mensurar, monitorar e recompensar o desempenho de seus funcionários, como por exemplo, o lucro para mensurar e monitorar o desempenho. Ou seja, a contabilidade possui importante papel na resolução dos conflitos de agência como fonte de informações úteis nesse processo de tomada de decisão, pois ao fornecer informações, como por exemplo, o lucro, que é utilizado como indicador de desempenho, ela torna possível à resolução ou minimização de determinado conflito de interesses entre principal e agente. Nesse sentido, Pires (2008) afirma que a contabilidade possibilita o aprimoramento das relações de agência, pois faz com que o ambiente onde estão inseridos principal e agente, apresente a possibilidade da inexistência de diferenças informacionais.

\subsection{TEORIA DA AGÊNCIA: ASPECTOS GERENCIAIS}

Para uma empresa obter vantagem competitiva ele necessita possuir competências essenciais que são fontes de vantagem competitiva. Competência essencial é o aprendizado coletivo na organização, que requer o envolvimento e comprometimento em trabalhar nesse ambiente empresarial, para que dessa forma, possam ser produzidas habilidades, que juntas, constituem a competência essencial, a qual não diminui com o uso, ao contrário, as competências se desenvolvem à medida que são aplicadas e compartilhadas (MONTGOMERY; PORTER, 1998). A remuneração baseada na performance e em medidas de desempenho, é uma das alternativas que podem ser utilizadas para contribuir com a obtenção de vantagem competitiva sustentável e alinhar os interesses entre principal e agente, e além disso para uma empresa, se caracteriza como mecanismo imprescindível para assegurar os níveis de rentabilidade desejados (INDJEJIKIAN; NANDA, 1999; DALMACIO; REZENDE; SLOMSKI, 2007).

Nesse sentido, uma vez que o funcionário e o proprietário da empresa estão com seus interesses alinhados em prol de um objetivo em comum, essa alinhamento de interesses contribui também com desenvolvimento da competência essencial, o que pode colaborar com a obtenção ou o aumento da vantagem competitiva da empresa. Dentro desse contexto, para Wagner III e Hollenbeck (2000) e Martins e Veriano (2004), muitos especialistas consideram atualmente as pessoas que formam uma organização, como a fonte primária de vantagem competitiva sustentável. Uma vez que determinada firma emprega os melhores funcionários, ela dispõe de uma fonte de vantagem competitiva que dificilmente será alcançada por outras empresas.

Uma alternativa para mudar os tradicionais programas de administração de salários é o uso da Remuneração Variável ou Flexível. Para Pontes (2002) a remuneração variável é o processo de remunerar os funcionários de forma a ter uma parte fixa e uma móvel. A parte fixa advém da definição de estruturas salariais, e a parte variável advém de outros fatores definidos e pactuados previamente, e que, geralmente levam em conta o desempenho do funcionário ou da sua equipe de trabalho e, principalmente, o desempenho da empresa. Conforme Bloom e 
Milkovich (1995), Pizutti (2000), Marquezan et al. (2014) e Tonani e Silva (2014) a remuneração variável é uma política de remuneração que pode alinhar os interesses dos empregados com os objetivos da empresa.

Entre os principais incentivos e indicadores de desempenho que determinadas empresas oferecem aos seus funcionários, destacam-se os mencionados na pesquisa de Oyadomari et al. (2009), intitulada Influências da Remuneração de Executivos na Congruência de Metas, pesquisa realizada com 21 empresas de grande porte, em que o grau de utilização de incentivos utilizados pelas empresas varia de 0 à 7 conforme dados da Tabela 1 a seguir:

Tabela 1: Prática de Remuneração Variável

\begin{tabular}{l|c}
\hline \multicolumn{1}{c|}{ Prática de Remuneração Variável } & Média \\
\hline Participação nos lucros e resultados & 6,9 \\
\hline Remuneração por mérito & 4,3 \\
\hline Incentivos individuais & 3,0 \\
\hline Remuneração por unid. prod./vendida & 2,1 \\
\hline Plano de bonificações em ações & 1,7 \\
\hline Recompensas não monetárias & 1,6 \\
\hline Prêmios em viagens e outros bens & 0,8 \\
\hline
\end{tabular}

Fonte: Adaptado de Oyadomari et al.

Conforme Oyadomari et al. (2009) e Mendes e Flach (2015) o programa de remuneração variável influencia, de alguma forma, o comportamento dos gestores em busca dos objetivos da organização, devido ao efeito motivador do sistema de remuneração variável enquanto incentivo monetário para obter desempenho. Percebe-se também que a contabilidade fornece informações que podem funcionar como medidas de desempenho auxiliando na resolução dos conflitos de agência.

Entretanto, nem sempre haverá relação entre os incentivos oferecidos aos funcionários de uma empresa com o desempenho desta, o que foi verificado na pesquisa de Teixeira et al. (2011), que analisou se ha relação entre os sistemas de incentivos gerenciais oferecidos aos gestores e o risco das empresas, concluindo pelo não mapeamento de relacionamento significativo entre os sistemas de incentivos oferecidos aos gestores e risco das empresas analisadas.

\subsection{PARTICIPAÇÃO NOS LUCROS E RESULTADOS}

Sobre a Participação nos Lucros ou Resultados, é importante ressaltar as principais diferenças entre Participação nos Lucros e Participação nos Resultados. De acordo com Marinakis (1997) a Participação nos Lucros tem como objetivo estabelecer uma ligação entre a remuneração dos funcionários com os objetivos da empresa (aumento nos lucros); o indicador de desempenho é o lucro; os funcionários são remunerados em dinheiro e a frequência de remuneração é anual ou semestral. Já a Participação nos Resultados tem como principal objetivo estimular o esforço individual ou coletivo dos empregados; o indicador de desempenho é a produtividade; os funcionários são remunerados em dinheiro e a frequência de remuneração pode ser mensal, trimestral ou semestral.

Sobre a importância de incentivos oferecidos por uma empresa aos seus funcionários com o intuito de alinhar os interesses entre principal e agente, falando especificamente sobre a Participação nos Lucros e Resultados (PLR), a pesquisa realizada por Oliveira (2005), destacou que a PLR gera nos funcionários de uma empresa, o sentimento de querer vencer e "fazer carreira" e a aspiração de vencer leva o indivíduo a trabalhar mais e melhor, produzindo efeitos de poder, garantindo o controle e a subordinação dos trabalhadores aos objetivos da organização. Para Maia (2003) o acompanhamento mensal da evolução dos indicadores que

GєCont, v. 5, n. 1, Floriano-PI, Jan-Jun. 2018. 
servem como base para a PLR, é uma forma que pode ser utilizada para tentar reduzir o efeito negativo do pagamento anual da PLR.

Lopes e Martins (2012) mencionam que o lucro da empresa é influenciado pelo cenário econômico, pela posição estratégica da empresa, além do chamado gerenciamento de resultados, que consiste na manipulação de ajustes, estes que são oriundos do regime de competência, de acordo com os interesses da empresa. Ou seja, os gestores da empresa podem manipular as despesas, por exemplo, para diminuir o lucro propositalmente, com o intuito de diminuir a participação dos funcionários no resultado da empresa.

Entretanto, quanto à restrição em relação ao uso do lucro como indicador de desempenho, pesquisa realizada por Lins (2006) sobre Status da Remuneração das Empresas Brasileiras, mostrou que entre os diferentes indicadores de desempenho mencionados na pesquisa, a remuneração com base no lucro foi a segunda mais utilizada pelas empresas entrevistadas (59\%), ficando atrás somente da remuneração com base no cargo (67\%). O que mostrou que o lucro é um indicador de desempenho muito utilizado e com contribuição importante na relação entre o esforço dos funcionários e o resultado da empresa.

Portanto, mesmo com certas restrições o Lucro utilizado como indicador de desempenho, pode ser uma boa ferramenta de auxílio na resolução dos conflitos de agência, porque pode estabelecer uma relação entre o desempenho dos funcionários e o resultado econômico da empresa, tornando possível o alinhamento de interesses entre principal e agente.

\section{METODOLOGIA}

Os dados desta pesquisa foram tratados de forma qualitativa. Para Martins e Theóphilo (2007) a pesquisa qualitativa é o estudo aprofundado de determinado fenômeno que visa compreender, interpretar e analisar dados que não são passíveis de serem expressos por dados numéricos. Esta pesquisa enquadra-se como uma pesquisa descritiva, que tem como principal objetivo descrever as características de determinado fenômeno, o que implica na análise e no registro do objeto estudado (MARION et al. 2002). Os dados foram coletados com base em uma pesquisa de campo e um estudo de caso. Conforme Vergara (2005), a pesquisa de campo é uma investigação empírica realizada no local onde corre ou ocorreu o fenômeno a ser estudado; para Triviños (1987), o estudo de caso tem como objeto de pesquisa uma unidade que se analisa aprofundadamente. Foram adotadas tais técnicas de pesquisa para este artigo, com o propósito de fazer um estudo mais profundo e específico sobre o fenômeno analisado.

Dessa forma, para coletar os dados da pesquisa utilizou-se uma única entrevista semiestruturada em uma Siderúrgica no Estado do Espírito Santo que utiliza a Participação nos Lucros e Resultados, na data de 19 de fevereiro de 2013. A unidade de coleta de dados foi escolhida por conveniência devido a acessibilidade dos dados. É importante destacar que a Analista de Remuneração que foi entrevistada, trata-se de uma profissional experiente em adoção de Participação nos Lucros e Resultados (PLR), e que a mesma possui acesso as informações sobre o desempenho dos trabalhadores da Siderúrgica em questão. O fato da entrevista semiestruturada realizada na Siderúrgica ter sido feita com uma única profissional, traz determinadas limitações a este artigo, dada a necessidade de se entrevistar um número maior de profissionais, ao utilizar-se essa técnica de coleta de dados. Nesse sentido, diante da impossibilidade de entrevistar uma quantidade maior de profissionais na empresa em questão, optou-se em utilizar pesquisa documental do Plano de Participação nos Lucros e Resultados (PPLR) dessa Siderúrgica, com o intuito de minimizar tais limitações, bem como aumentar a quantidade de informações sobre a relação entre PLR e desempenho dessa unidade empresarial.

A entrevista semiestruturada em que a Analista de Remuneração da empresa em questão respondeu as perguntas da entrevista, teve 3 horas de duração ao todo; e foi elaborada por meio de um roteiro com questões abertas, estas que foram criadas com base nos pressupostos que 
compõem a plataforma teórica da pesquisa a fim de atingir os objetivos deste artigo. A pesquisa documental do PPLR da Siderúrgica, trata-se de um documento que contém todas as informações referentes à estrutura e funcionalidade do plano de participação nos lucros e resultados, além de um controle interno com todas as metas e normas, cuja finalidade consiste em garantir a aplicação de forma eficiente da participação dos empregados nos lucros e resultados da empresa.

Segundo Martins e Theóphilo (2007) a entrevista semiestruturada é conduzida por meio de um roteiro, mas com a possibilidade do entrevistador acrescentar novas questões no momento da entrevista. A entrevista realizada na Siderúrgica foi orientada por um roteiro com questões abertas. De acordo com Beuren (2008) o questionário aberto ou livre é aquele que permite ao entrevistado responder livremente as perguntas, possibilitando a obtenção de respostas com maior grau de informação. A pesquisa documental ou de fontes primárias trabalha com informações que não receberam tratamento analítico, ou seja, trata-se de dados que não foram editados, por isso, ela é também conhecida como pesquisa de fontes primárias (BEUREN, 2008).

Através da análise de conteúdo, todas as informações coletadas foram analisadas e interpretadas à luz do referencial teórico e dos objetivos da pesquisa. De acordo com Martins e Theóphilo (2007) a análise de conteúdo busca a essência de um texto nos detalhes das informações, o interesse não se restringe à descrição dos conteúdos, deseja-se inferir sobre o todo, buscando compreender os efeitos e consequências dessas informações. Por fim, todos os dados após serem coletados, preparados e organizados foram confrontados com o problema da pesquisa e os objetivos da pesquisa, conduzindo dessa forma, a análise e interpretação dos dados obtidos para as considerações finais da pesquisa.

\section{DESCRIÇÃO E ANÁLISE DOS RESULTADOS}

Neste tópico abordou-se a descrição e análise do Plano de Participação nos Lucros e Resultados (PPLR) e da entrevista semiestruturada, conforme a coleta de dados realizada na Siderúrgica localizada no Estado do Espírito Santo. Para manter o sigilo das informações que foram coletadas na Siderúrgica, adotou-se a convenção de denominá-la de Empresa Alpha.

4.1 DESCRIÇÃO E ANÁLISE DO PLANO DE PARTICIPAÇÃO NOS LUCROS E RESULTADOS DA EMPRESA ALPHA

A unidade de coleta de dados, a Empresa Alpha, é situada no Estado do Espírito Santo, a empresa é a maior produtora de aço da América Latina, em relação à unidade do Espírito Santo em que foi feita a coleta de dados, a empresa possui aproximadamente 5.000 (cinco mil) funcionários (dados obtidos através da entrevista realizada na empresa em 19 de fevereiro de 2013).

4.1.1 Plano de Participação dos Funcionários da Empresa Alpha em seus Resultados

O Plano de Participação nos Lucros e Resultados (PPLR) da empresa é composto pela participação nos resultados por metas e participação no lucro/resultado global.

Participação nos Resultados por Metas - Bônus: é a parcela da PLR vinculada ao alcance das metas estabelecidas para cada período. É concedido um bônus em dinheiro aos empregados, com base em um percentual aplicado sobre a quantidade de salários praticados no ano, que corresponde a 14 salários (12 salários + 13º salário + abono legal/gratificação de férias).

O estabelecimento de metas no contexto da PLR funciona sob o ponto de vista da Analista de Remuneração da empresa em questão, como um importante estímulo aos empregados dessa empresa, contribuindo com o aumento da motivação dos funcionários, dessa forma, possivelmente pode proporcionar um alinhamento de interesses entre principal a agente, podendo manter a relação entre proprietário e funcionários estável. O que ratifica os resultados da pesquisa de Becker (1998), Gheller (2001) e Maia (2003) que constaram que a adoção da 
PLR, trouxe contribuições no desempenho dos funcionários, gerando aumento da eficiência destes, alinhando os interesses entre principal e agente.

Participação nos Lucros/Resultado Global: é a parcela da PLR a ser paga em função do lucro gerado pelo negócio da Empresa Alpha. É concedida a participação no resultado da empresa, 2\% do EBITDA proporcional aos salários dos empregados, se a meta de Retorno do Capital Empregado (ROCE) for alcançada. O ROCE será revisto e fixado anualmente, pela Diretoria da Empresa Alpha.

O termo ROCE é o lucro operacional - (menos) impostos $\div$ (dividido) pelo capital investido (COPELAND et al. 1996). O termo EBITDA (Earnings Before Interest, Taxes, Depreciation and Amortization) é o lucro antes dos juros, impostos, depreciação e amortização (LAJIDA) (MARTINS et al. 2012). Conforme Santos e Schmidt (2011) a Demonstração do Valor Adicionado (DVA) é uma demonstração contábil que tem o objetivo de apresentar de forma ordenada e sintética, a riqueza gerada por uma empresa em determinado período e sua distribuição.

Portanto, a Participação nos Lucros/Resultado Global tem como objetivo estabelecer uma ligação entre a remuneração dos funcionários (concessão de incentivos financeiros) com os objetivos da empresa (aumento nos lucros). Enquanto a Participação nos Resultados por Metas - Bônus tem como principal objetivo estimular o esforço dos funcionários. Entretanto, tanto a participação nos lucros quanto a participação nos resultados contribuem para alinhar os interesses entre principal e agente na Empresa Alpha. Esse mecanismo de gestão também tornou possível modernizar a estrutura de remuneração da empresa em questão, corroborando com as evidências da pesquisa de Becker (1998).

O lucro contábil é uma importante ferramenta utilizada como parâmetro para a participação dos empregados nos lucros que funciona como indicador de desempenho, fornecendo informações úteis nesse processo de tomada de decisão utilizado na Empresa Alpha. O que corrobora com a pesquisa de Pires (2008) que menciona que a contabilidade possibilita o aprimoramento das relações de agência, reduzindo as diferenças informacionais no ambiente empresarial.

Com base na análise de conteúdo realizado do Plano de Participação nos Lucros e Resultados (PPLR) da Empresa Alpha, notou-se um elevado grau de complexidade na estrutura desse plano, trata-se de um documento extenso em relação a quantidade de informações, o que exige certo nível de conhecimento de ferramentas gerencias e sobre implantação de PPLR, para que seja possível obter resultados ótimos na implantação desse mecanismo de gestão.

4.1.2 Critérios para Pagamento da PLR e Definição de Meta da Empresa Alpha

Dos critérios para pagamento da participação nos resultados por metas - bônus e participação no lucro/resultado global são feitos conforme o Quadro 1 a seguir:

\section{Quadro 1: Critérios para Pagamento das Participações}

\begin{tabular}{|l|l|l|}
\hline \multicolumn{1}{|c|}{ Critério } & Participação nos Resultados & \multicolumn{1}{c|}{ Participação nos Lucros } \\
\hline Pagamento & Anual & Anual \\
\hline Proporcionalidade (\%) & Metas atingidas & EBTIDA \\
\hline
\end{tabular}

Fonte: Elaborado pelos autores com base na pesquisa documental e na entrevista

As metas a serem alcançadas pelos empregados em relação ao Plano de Participação nos Lucros e Resultados (PPLR) são definidas pela Empresa Alpha deste modo: é um objetivo claro, possível e mensurável trazendo retorno positivo à Companhia a partir do esforço e comprometimento do empregado. As metas devem abranger todos os empregados e devem ser: simples, mensuráveis e atingíveis; homogêneas e niveladas para todos os órgãos, objetivando a exigência de esforços similares e equilibrados a todos os empregados. Através da definição de metas feita pela empresa Alpha, verificou-se que entre os principais desafios de implantação do 
PPLR, foram o elevado grau de conhecimento de ferramentas gerenciais e estabelecimentos de critérios pré-definidos e bem elaborados para que exista uma aderência ótima entre metas planejadas e metas executadas.

4.1.3 Metas Comportamentais, Metas Gerenciais, Metas de Desempenho Operacional e Administrativo

Metas Comportamentais: são metas relativas às atitudes e condutas dos empregados no contexto da companhia. Metas Gerenciais: são metas relativas aos objetivos relacionados aos aspectos de gestão de pessoas. Metas de Desempenho Operacional e Administrativo: são as metas relacionadas aos processos técnicos, operacionais e administrativos de cada setor.

Todas as metas devem ser cumpridas integralmente, caso contrário, a PLR de todos os funcionários sofrerá redução. Sobre a importância do estabelecimento de metas para a equipe de trabalho da Empresa Alpha, os benefícios gerados pelas metas estabelecidas foram evidenciados no Quadro 2 a seguir:

Quadro 2: Relação entre Metas Estabelecidas e Benefícios Gerados

\begin{tabular}{|c|c|c|}
\hline Metas Estabelecidas & Benefícios & Benefícios Econômicos \\
\hline $\begin{array}{l}\text { Redução de desperdícios na } \\
\text { alimentação }\end{array}$ & $\begin{array}{l}\text { Otimização de recursos e } \\
\text { disciplina }\end{array}$ & $\begin{array}{l}\text { Aumento do lucro devido à redução das } \\
\text { despesas com alimentação dos } \\
\text { empregados }\end{array}$ \\
\hline $\begin{array}{l}\text { Programa de acompanhamento e } \\
\text { desenvolvimento do funcionário }\end{array}$ & $\begin{array}{l}\text { Maximização } \\
\text { eficiência da equipe de } \\
\text { trabalho o que aumenta a } \\
\text { fonte de vantagem } \\
\text { competitiva da empresa } \\
\text { entre as demais } \\
\text { concorrentes no mercado }\end{array}$ & $\begin{array}{l}\text { Aumento do lucro devido à redução de } \\
\text { gastos com a identificação/substituição } \\
\text { de funcionários com rendimento abaixo } \\
\text { do esperado }\end{array}$ \\
\hline Vendas regionais & $\begin{array}{l}\text { Busca frequente pela } \\
\text { superação de limites }\end{array}$ & $\begin{array}{l}\text { Aumento/manutenção do volume de } \\
\text { vendas do período }\end{array}$ \\
\hline Setor jurídico & $\begin{array}{l}\text { Conscientização da equipe } \\
\text { de trabalho sobre redução } \\
\text { de gastos }\end{array}$ & $\begin{array}{l}\text { Aumento do lucro devido à redução das } \\
\text { despesas administrativas }\end{array}$ \\
\hline
\end{tabular}

Fonte: Elaborado pelos autores com base na pesquisa documental e na entrevista

Com base nos dados do quadro 2 anterior, observa-se que embora sejam metas distintas, todas elas possuem benefícios em comum: quanto aos benefícios no desempenho dos funcionários: otimização de recursos e disciplina, o que aumenta o grau de eficiência da mão de obra desses funcionários; quanto aos benefícios econômicos: redução de despesas que contribuem com o aumento do lucro da unidade empresarial. Todos os esses benefícios gerados para a Empresa Alpha citados no quadro 2 anterior, conforme relatou a Analista de Remuneração da empresa, só foram alcançados devido ao fato de que a firma conseguiu alinhar os interesses entre proprietários/diretoria e funcionários através da Participação nos Lucros e Resultados (PLR).

Quanto à meta comportamental de redução de desperdício na alimentação a Empresa Alpha conforme relatou a Analista de Remuneração da referida empresa, conseguiu reduzir o desperdício na alimentação dos funcionários de forma bastante significativa, de modo que tal desperdício chegou a praticamente zero. Tal meta, além de alinhar os interesses entre principal e agente, afinal, ambos possuem o objetivo de não desperdiçar os alimentos oferecidos pela empresa, também auxilia com a redução da despesa com alimentação da entidade o que contribui para o aumento da lucratividade da empresa. O que foi possível, devido à aplicação dessa meta, que é um dos requisitos para que os funcionários tenham direito a participação nos resultados da empresa. Tais benefícios comportamentais e econômicos são oriundos da aplicação da PLR, que é uma espécie de remuneração variável, o que corrobora com as 
evidências das pesquisas de (INDJEJIKIAN; NANDA, 1999; DALMACIO; REZENDE; SLOMSKI, 2007).

Conforme os dados obtidos pela aplicação da entrevista construiu-se o Quadro 3 a seguir, que relaciona os objetivos do PPLR da Empresa Alpha com os benefícios gerados por tais objetivos:

\section{Quadro 3: Relação entre Objetivos Específicos e Benefícios Gerados}

\begin{tabular}{|l|l|}
\hline \multicolumn{1}{|c|}{ Objetivos Específicos } & \multicolumn{1}{|c|}{ Benefícios Gerados } \\
\hline $\begin{array}{l}\text { Compartilhar ganhos com empregados de acordo com } \\
\text { os resultados alcançados }\end{array}$ & $\begin{array}{l}\text { Aumento do grau de eficiência da mão de obra dos } \\
\text { empregados }\end{array}$ \\
\hline Reconhecer a busca por desafios & Estimular a equipe de trabalho \\
\hline $\begin{array}{l}\text { Modernizar e alinhar o plano às atuais práticas de } \\
\text { mercado }\end{array}$ & $\begin{array}{l}\text { Conquista/manutenção da competência essencial da } \\
\text { empresa entre as demais concorrentes no mercado }\end{array}$ \\
\hline $\begin{array}{l}\text { Alinhar e comprometer equipes com os planos } \\
\text { operacionais estabelecidos }\end{array}$ & $\begin{array}{l}\text { Garantir o sucesso do plano de participação nos lucros } \\
\text { e resultados }\end{array}$ \\
\hline Proporcionar clareza de objetivos a serem atingidos & $\begin{array}{l}\text { Garantir o sucesso do plano de participação nos lucros } \\
\text { e resultados }\end{array}$ \\
\hline Atrair e reter profissionais & $\begin{array}{l}\text { Possuir funcionários altamente qualificados e } \\
\text { comprometidos }\end{array}$ \\
\hline
\end{tabular}

Fonte: Elaborado pelos autores com base na entrevista

É possível notar que o objetivo da Empresa Alpha ao implantar a PLR é de alinhar os interesses entre proprietários/diretoria e empregados, conseguindo desse modo, sob o ponto de vista da Analista de Remuneração da referida empresa, reduzir os conflitos de agência e garantir dessa forma, os diversos benefícios gerados para a empresa conforme descritos no quadro 3 anterior, confirmando as evidências da pesquisa de Maia (2003).

Verificou-se por meio da análise de conteúdo do PPLR e da entrevista semiestruturada aplicados na empresa Alpha, que para o PPLR gerar resultados ótimos, as metas traçadas que compõem o mesmo devem ser claras, concisas e objetivas, no sentido de serem inteligíveis e alcançáveis pelos empregados da empresa. Pois, se uma meta não for compreendida, ela não será alcançada; e se a meta for compreendida, mas for exagerada em seu propósito, torna-se impossível alcançá-la, tal problema desmotiva os empregados inviabilizando o cumprimento dessa meta.

\subsubsection{Histórico da Distribuição da Participação nos Lucros e Resultados da Empresa Alpha}

Com base na entrevista realizada na empresa construiu-se o histórico da distribuição da Participação nos Lucros e Resultados (PLR) de 2006 a 2010, com a distribuição do número de salários acrescidos nas remunerações de cada funcionário da Empresa Alpha, conforme a Tabela 2 a seguir:

Tabela 2: Histórico da Distribuição da PLR da Empresa Alpha

\begin{tabular}{c|c|c}
\hline Ano & Participação nos Resultados & Participação nos Lucros \\
\hline 2006 & 1,37 & 2,9 \\
\hline 2007 & 1,37 & 3,93 \\
\hline 2008 & 1,37 & 4,8 \\
\hline 2009 & 1,37 & 0 \\
\hline 2010 & 0 & 4,65 \\
\hline
\end{tabular}

Fonte: Elaborado pelos autores com base na entrevista

Com base nos dados da tabela 2 anterior, verifica-se que em praticamente todos os anos houveram distribuição de Participação nos Resultados (PR) e Participação nos Lucros (PL), no caso da PL representa um acréscimo significativo na remuneração dos funcionários da Empresa 
Alpha, como exemplo no ano de 2010, que somente a PL gerou um acréscimo de 4,65 salários para cada funcionários além da PR.

Ainda no que se refere à análise dos dados da tabela 4 anterior, nota-se que em relação a alguns anos não houveram distribuição de PR nem de PL e que a distribuição de PR se manteve linear em todos os anos, essas informações não significam que houve baixa distribuição de PR e PL para os funcionários da Empresa Alpha, o que pode ser verificado na Tabela 3 a seguir, sobre dados da Demonstração do Valor Adicionado (DVA) da Empresa Alpha.

Tabela 3: Dados da Demonstração do Valor Adicionado da Empresa Alpha

\begin{tabular}{l|l|l|l|l|l}
\hline \multicolumn{5}{c}{ Participação dos Empregados nos Lucros (Valores em Milhares de Reais) } \\
\hline $\mathbf{2 0 1 0}$ & $\mathbf{2 0 0 9}$ & $\mathbf{2 0 0 8}$ & $\mathbf{2 0 0 7}$ & $\mathbf{2 0 0 6}$ & $\mathbf{2 0 0 5}$ \\
\hline 192.465 & 146.701 & 234.053 & 195.814 & 157.113 & 101.678 \\
\hline
\end{tabular}

Fonte: Elaborado pelos autores com base na DVA da Empresa Alpha

Comparando os dados da tabela 3 anterior, com os dados da tabela 4 anterior, percebese que no ano de 2009 em que a PL registrou distribuição igual à zero, neste mesmo ano o valor da participação dos empregados nos lucros foi de 146.701 (valor em milhares de Reais); e em relação ao ano de 2010 que registrou distribuição de PR igual à zero, neste mesmo ano o valor da participação dos empregados nos lucros foi de 192.465 (valores em milhares de Reais), o que sugere que a empresa distribui anualmente parte dos seus resultados com seus funcionários. Vale lembrar, que os dados da DVA que constam na tabela 5 anterior, fazem parte das demonstrações financeiras de todo o grupo da Empresa Alpha e não somente da unidade em que foi realizada a pesquisa documental do Plano de Participação nos Lucros e Resultados (PPLR) e a entrevista semiestruturada.

É importante destacar que a empresa que adotar a PLR, terá um aumento nas despesas com remuneração de funcionários, devido à distribuição da PLR entre seus empregados, entretanto, os benefícios gerados pela PLR são maiores do que os gastos originados por ela, além de todos os exemplos de empresas que têm bons resultados na utilização da PLR citados no referencial teórico, tais como as pesquisas de Maia (2003), Fochesatto (2002) e Gheller (2001), entre outras. A Empresa Alpha conforme relatou a Analista de Remuneração da referida empresa, utiliza a PLR desde o ano de 1995, totalizando 18 anos de utilização da PLR. Esse longo tempo que a empresa a utiliza, se justifica pelo fato de que os benefícios gerados pela PLR são superiores aos gastos gerados por ela, conforme destacou a Analista de Remuneração da Empresa Alpha.

Vale ressaltar a relação que a PLR possui com o desempenho econômico da Empresa Alpha, entre os diversos benefícios gerados pela PLR mencionados pela Analista de Remuneração da empresa, entre eles destaca-se a redução da despesa com alimentação, provocados pela redução dos desperdícios com alimentação por parte dos funcionários da empresa, fato esse, que só foi possível devido ao cumprimento de metas pelos funcionários, para que assim tenham direito a receber a PLR. O que para a Empresa Alpha, contribui para o aumento de sua lucratividade dada à redução na despesa com alimentação dos funcionários.

Com base na entrevista realizada com a Analista de Remuneração da empresa Alpha, construiu-se o Quadro 4 a seguir, com os trechos mais relevantes. 
Quadro 4: Principais Perguntas e Respostas da Entrevista Semiestruturada

\begin{tabular}{|c|c|}
\hline Perguntas & Respostas \\
\hline Qual foi o objetivo da empresa ao implantar o PPLR? & $\begin{array}{l}\text { Estimular e premiar os empregados no alcance de } \\
\text { resultados e alinhar os empregados com os objetivos } \\
\text { da Siderúrgica; modernizar e alinhar o plano às atuais } \\
\text { práticas de mercado, garantindo a competitividade da } \\
\text { política de remuneração da empresa; alinhar e } \\
\text { comprometer equipes com os planos operacionais } \\
\text { estabelecidos; atrair e reter profissionais. }\end{array}$ \\
\hline $\begin{array}{l}\text { Quais os principais fatores que poderiam contribuir } \\
\text { para um maior grau de estímulo para que mais } \\
\text { empresas do Espírito Santo (ES) implantassem o } \\
\text { PPLR? }\end{array}$ & $\begin{array}{l}\text { Maior ênfase em benefícios mais específicos gerados } \\
\text { pela PLR, fatores como aumento motivacional e } \\
\text { aumento da produtividade dos funcionários, deveriam } \\
\text { ser divulgados para estimular mais empresas no ES a } \\
\text { implantarem a PLR, além dos benefícios fiscais que } \\
\text { são normalmente divulgados. }\end{array}$ \\
\hline $\begin{array}{l}\text { O PPLR que a empresa oferece aos funcionários faz } \\
\text { com que e os funcionários exerçam as funções deles } \\
\text { com mais eficiência? }\end{array}$ & $\begin{array}{l}\text { A PLR proporciona um estimulo significativo no } \\
\text { desempenho dos funcionários da empresa, os } \\
\text { funcionários ao saberem que o acréscimo na } \\
\text { remuneração deles depende do empenho destes no } \\
\text { cumprimento das metas traçadas pela entidade, dessa } \\
\text { forma, os funcionários são significativamente } \\
\text { influenciados pela PLR, aumentando assim o grau de } \\
\text { eficiência não só nos serviços prestados por eles, mas, } \\
\text { também no seu comportamento de modo geral na } \\
\text { empresa. }\end{array}$ \\
\hline $\begin{array}{l}\text { As metas implantadas para que os funcionários } \\
\text { recebam o PPLR, fez de alguma forma a empresa } \\
\text { reduzir despesa de maneira que contribua no } \\
\text { desempenho econômico? }\end{array}$ & $\begin{array}{l}\text { Sim, as metas implantadas também impacta no } \\
\text { desempenho econômico da empresa, como as metas } \\
\text { relacionadas a redução de desperdícios com refeições } \\
\text { oferecidas aos funcionários que refletiu de modo que } \\
\text { os mesmos reduzissem drasticamente o desperdício } \\
\text { das refeições, e isso representa para a empresa uma } \\
\text { redução na Despesa Com Alimentação dos } \\
\text { funcionários, o que irá gerar para ela entre outros } \\
\text { benefícios, um aumento em sua lucratividade. }\end{array}$ \\
\hline
\end{tabular}

Fonte: Elaborado pelos autores com base na entrevista

Nota-se que a empresa Alpha conforme dados do quadro 4 anterior, além de mencionar os diversos benefícios ao adotar o PPLR de modo geral, a empresa que possui experiência em adoção de PPLR, mencionou especificamente a importância de divulgação dos benefícios gerados, quanto a comportamento e produtividades dos funcionários provocados pelo PPLR, e não somente os benefícios fiscais, tal como ocorre normalmente, no intuito de estimular que mais empresas possam implantar esse programa.

\section{CONSIDERAÇÕES FINAIS}

A teoria da agência pressupõe a existência de conflitos de interesse entre principal e agente em um ambiente organizacional, nesse ambiente conflituoso, figuram determinados mecanismos de gestão capazes de alinhar os interesses entre proprietários e funcionários de uma empresa. Dentro desse contexto. Objetivou-se neste artigo verificar os desafios e benefícios de um programa de participação nos lucros e resultados de uma Siderúrgica localizada no Estado do Espírito Santo. Para alcançar os objetivos deste artigo realizou-se um estudo na Empresa Alpha situada no Estado do Espírito Santo, por meio de pesquisa documental do PPLR e de entrevista semiestruturada com a Analista de Remuneração dessa Siderúrgica.

Quanto aos desafios inerentes à adoção do PPLR os resultados indicam que o PPLR possui elevado grau de complexidade em sua estrutura quanto a quantidade de informações, o 
que exige certo nível de conhecimento de ferramentas gerencias e sobre implantação de PPLR, para que seja possível obter resultados ótimos na implantação desse mecanismo de gestão. Bem como o estabelecimento de critérios pré-definidos e bem elaborados para que exista uma aderência ótima entre metas planejadas e metas executadas. As metas que compõem o PPLR devem ser claras e objetivas, no sentido de serem compreensíveis e alcançáveis pelos empregados da empresa. Pois, se uma meta não for compreendida, ela não será alcançada; e se a meta for compreendida, mas for exagerada em seu propósito, torna-se impossível alcançá-la, tal problema desmotiva os empregados inviabilizando o cumprimento dessa meta.

No que se refere aos benefícios gerados pela implantação do PPLR os resultados encontrados sob o ponto de vista da Analista de Remuneração da Empresa Alpha, sugerem que a distribuição dos recursos gerados pela unidade empresarial entre seus funcionários exerce influência no desempenho desses funcionários, fazendo com que eles trabalhem de forma mais eficiente, tornando possível alinhar os interesses entre principal e agente; e que a distribuição dos recursos gerados pela Empresa Alpha entre seus empregados contribui com o desempenho econômico dessa unidade empresarial, trazendo redução em diversos gastos, o que possivelmente pode contribuir para um aumento do lucro da empresa. Destaca-se também os benefícios de modernização de Estrutura de Remuneração e aumento da capacidade de atrair e reter funcionários. Confirmando os resultados obtidos pelas pesquisas citadas ao longo do referencial teórico que também evidenciaram os benefícios comportamentais e econômicos que os incentivos financeiros podem trazer para uma organização e seus funcionários.

Portanto, para que uma empresa possa obter os benefícios de um PPLR é necessário que seja feito um bom planejamento e exige-se alto grau de conhecimento de ferramentas gerencias, para que esse controle interno seja eficiente, uma vez que o PPLR é elaborado com o intuito de afetar o comportamento de seres humanos envolvidos na organização, estes que são indivíduos com atitudes e comportamentos complexos e imprevisíveis. Dentro desse contexto, faz-se necessário a adoção de um caráter criterioso e rigoroso quanto as metas estabelecidas, bem como os propósitos que a empresa deseja que seus empregados alcancem. Nesse sentido, como o PPLR é aplicado a indivíduos aos quais devido a sua complexidade e imprevisibilidade não são passíveis de serem controlados por completo, embora o PPLR possa para diversas empresas afetar positivamente o comportamento dos indivíduos nelas inseridos, isso não significa que todas as organizações terão também resultados positivos.

Desse modo, entende-se que este artigo contribuiu para a ampliação do entendimento do fenômeno estudado, ao levantar informações sobre adoção de um PPLR evidenciando os desafios, benefícios e sua estrutura e principais características; e ao confirmar sob o ponto de vista da Analista de Remuneração da Empresa Alpha, a premissa levantada pela teoria da agência de que, a concessão de incentivos ou gratificações a funcionários de uma organização, permite que uma empresa consiga alinhar os interesses entre principal e agente, reduzindo os conflitos de agência entre os indivíduos dessa unidade empresarial.

Diante do exposto, é importante ressaltar que os resultados encontrados por este artigo não são generalizáveis, ou seja, os dados que foram analisados para responder o problema de pesquisa deste artigo se referem a uma empresa específica, e como cada unidade empresarial possui realidades distintas, os resultados obtidos com base nos dados da empresa em que os dados foram coletados podem ser diferentes dos possíveis resultados de outras empresas.

Portanto, os resultados deste artigo remetem a reflexões e novas pesquisas sobre o fenômeno estudado. Ressalta-se a limitação metodológica deste artigo quanto a coleta dos dados pela entrevista realizada com a Analista de Remuneração da empresa Alpha, as inferências feitas pelo presente artigo foram realizadas conforme o entendimento dessa profissional em relação aos benefícios e desafios do PPLR, por isso, as inferências deste estudo possuem os vieses da respondente da entrevista semiestruturada. 
Como sugestão para pesquisas futuras sugere-se que sejam analisadas uma quantidade maior de empresas, se possível todas as empresas de um determinado setor, com o intuito de poder fazer generalizações dos resultados encontrados em relação ao setor que foi analisado.

\section{REFERÊNCIAS}

AQUINO, A. C. B. de; CARDOSO, R. L.; MÁRIO, P. do C. Contabilidade gerencial: mensuração, monitoramento e incentivos. São Paulo: Atlas, 2007.

BAEK, J.-S.; KANG, J.-K.; PARK, K. S. Corporate governance and firm value: evidence form the Korean financial crisis. Journal of Financial Economics, v. 71, p. 265-313, feb. 2004.

BAILEY, C. D.; BROWN, L. D.; COCCO, A. F. The effects of monetary incentives on worker learning and performance in an assembly task. Journal of Management Accounting Research, n. 10, p. 119-131, 1998.

BAKER, G. P.; JENSEN, M.C.; MURPHY, K. J. Compensation and incentives: practice vs. theory. The Journal of Finance, v. 43, n. 3, p. 593-616, 1988.

BEBCHUK, L. A.; WEISBACH, M. S. The state of corporate governance research. Review of Financial Studies, v. 23, n. 3, p. 939-961, 2010.

BECHT, M.; BOLTON, P.; RÖELL, A. Corporate governance and control. 2002. Working Paper.

BECKER, G. V. Aplicação de programas de participação nos lucros ou resultados como estratégia de comprometimento na gestão de recursos humanos. 1998. 191 f. Dissertação (Mestrado em Administração) - Programa de Pós-Graduação em Administração, Universidade Federal do Rio Grande do Sul, Porto Alegre.

BERLE, A. A.; MEANS, G. C. The modern corporation and private property. New York: MacMillan, 1932.

BERNARDINO, F. F. M.; PEIXOTO, F. M.; FERREIRA, R. do N. Governança e eficiência em empresas do setor elétrico brasileiro. Pretexto, Belo Horizonte, v. 16, n. 1, p. 36-51, jan./mar. 2015.

BESANKO, D. et al. A economia da estratégia. 3. ed. Porto Alegre: Bookman, 2006.

BEUREN, I. M. (Org.). Como elaborar trabalhos monográficos em contabilidade: teoria e prática. 3. ed. São Paulo: Atlas, 2006.

BLOOM, M. C.; MILKOVICH, G. T. The relationship between risk, performance-based pay, and organizational performance. 1995. Working Paper.

BONNER, S. E.; SPRINKLE, G. B. The effects of monetary incentives on effort and task performance: theories, evidence, and a framework for research. Accounting, Organizations, and Society, v. 27, p. 303-345, 2002.

COPELAND, T.; KOLLER, T. \& MURRIN, J. Valuation: measuring and managing the value of companies, 2nd ed. New York: John Wiley \& Son, Inc. 1996.

CORREIA, L. F.; AMARAL, H. F. Reflexão sobre as funções da governança corporativa. Revista de Gestão USP, São Paulo, v. 13, p. 43-55, jan./mar. 2006. 
DALMACIO, F. Z.; REZENDE, A. J.; SLOMSKI, V. Medidas de performance como determinantes de remuneração dos gestores: méritos do gestor ou características do setor? CONGRESSO INTERNACIONAL DE CUSTOS, 2007, Lyon (França). Anais... p. 01-17.

DEVERS, C. E. et al. Executive compensation: a multidisciplinary review of recent developments. Journal of Management, v. 33, n. 6, p. 1016-1072, dec. 2007.

DROBETZ, W.; SCHILLHOFER, A.; ZIMMERMANN, H. Corporate governance and expected stock returns: evidence from Germany. 2003. Working Paper.

ELDENBURG, L. G.; WOLCOTT, S. K. Como medir, monitorar e motivar o desempenho. Rio de Janeiro: LTC, 2007.

FAMA, E. F.; JENSEN, M. C. Separation of ownership and control. Journal of Law and Economics, v. 26, n. 2, p. 301-325, jun. 1983.

FELTHAM, G. A.; XIE, J. Performance measure congruity and diversity in multi-task principal/agent relations. The Accounting Review, v. 69, n. 3, p. 429-453, jul. 1994.

FOCHESATTO, S. A. Os planos de incentivos e recompensas como fatores de motivação: estudos de caso nas duas maiores empresas do ramo metal-mecânico de Caxias do Sul. 2002. 136 f. Dissertação (Mestrado em Administração) - Programa de Pós-Graduação em Administração, Universidade Federal do Rio Grande do Sul, Porto Alegre.

GHELLER, J. A. Efeitos no comportamento dos funcionários de uma empresa de joias com a implantação de um programa de participação nos lucros e resultados. 2001. 109 f. Dissertação (Mestrado em Administração) - Programa de Pós-Graduação em Administração, Universidade Federal do Rio Grande do Sul, Porto Alegre.

GOYAL, V. K.; PARK, C. W. Board leadership structure and CEO turnover. Journal of Corporate Finance, v. 8, n. 1, p. 49-66, jan. 2002.

INDJEJIKIAN, R.; NANDA, D. Dynamic incentives and responsibility accounting. Journal of Accounting and Economics, v. 27, p. 177-201, 1999.

JENSEN, M. C.; MECKLING, W.H. Theory of the firm: managerial behavior, agency costs and ownership structure. Journal of Financial Economics, v. 3, n. 4, p. 305-360, oct. 1976.

JENSEN, M. C. Agency costs of free cash flow, corporate finance, and takeovers. The American Economic Review, v. 76, n. 2, p. 323-329, may 1986.

JENSEN, M. C. Self-interest, altruism, incentives, \& agency theory. Journal of Applied Corporate Finance, v. 7, n. 2, 1994.

LAMBERT, R. A. Contracting theory and accounting. Journal of Accounting and Economics, v. 32, p. 3-87, jan. 2001.

LINS, J. Remuneração variável, alavanca para o crescimento. Revista CEO Brasil, Price Water House e Coopers, n. 8, 2006.

LOPES, A. B.; MARTINS, E. Teoria da contabilidade: uma nova abordagem. São Paulo: Atlas, 2012.

LOUZADA, L. C.; SILVA JUNIOR, A.; RODY, P. H. A. Relação entre distribuição de resultados e o desempenho de uma unidade empresarial: uma abordagem da teoria da agência. In: CONGRESSO NACIONAL DE ADMINISTRAÇÃO E CIÊNCIAS CONTÁBEIS, 4., 2013, Rio de Janeiro. Anais... Rio de Janeiro: ADCONT , 2013. 
MAIA, P. A. A. O impacto dos programas de participação nos lucros ou resultados (PLRS) sobre o comprometimento e motivação dos trabalhadores no âmbito das cooperativas de eletrificação rural do Rio Grande do Sul: estudos de caso da Certaja, Certel e Creluz. 2003. 166 f. Dissertação (Mestrado em Administração) - Programa de PósGraduação em Administração, Universidade Federal do Rio Grande do Sul, Porto Alegre.

MARINAKIS, A. E. A participação dos trabalhadores nos lucros e resultados das empresas no Brasil: um instrumento para acelerar a reestruturação necessária. Revista de Administração de Empresas, São Paulo, v. 37, n. 4, p. 56-64, out./dez. 1997.

MARION, J. C.; DIAS, R.; TRALDI, M. C. Monografia para os cursos de administração, contabilidade e economia. São Paulo: Atlas, 2002.

MARQUEZAN, L. H. F. et al. Práticas de governança corporativa da bm\&fbovespa e o uso da remuneração variável para executivos. In: CONGRESSO DA ASSOCIAÇÃO

NACIONAL DOS PROGRAMAS DE PÓS-GRADUAÇÃO EM CIÊNCIAS CONTÁBEIS, 8., 2014, Rio de Janeiro. Anais... São Paulo: ANPCONT, 2014.

MARTINS, E.; DINIZ, J. A.; MIRANDA, G. J. Análise avançada das demonstrações contábeis: uma abordagem crítica. São Paulo: Atlas, 2012.

MARTINS, G. de A. Manual para elaboração de monografias e dissertações. São Paulo: Atlas, 2007.

MARTINS, G. de A.; THEÓPHILO, C. R. Metodologia da investigação científica para ciências sociais aplicadas. São Paulo: Atlas, 2007.

MARTINS, S. S.; VERIANO, C. E. A remuneração flexível como componente da gestão de salários. Revista de Administração de Empresas, Minas Gerais, v. 44, p. 22-33, abr./dez. 2004.

MENDES, A. C. A.; FLACH, L. Evidências sobre a influência da remuneração no comportamento dos funcionários em ambiente hospitalar: um estudo na região Sul do Brasil. In: CONGRESSO DA ASSOCIAÇÃO NACIONAL DOS PROGRAMAS DE PÓSGRADUAÇÃO EM CIÊNCIAS CONTÁBEIS, 9., 2015, Curitiba-PR. Anais... São Paulo: ANPCONT, 2015.

MONTGOMERY, C. A.; PORTER, M. E. (Org.). Estratégia: a busca da vantagem competitiva. Rio de Janeiro: Elsevier, 1998.

OLIVEIRA, F. M. Dos S. Conflitos, gestão e poder: um estudo de caso em uma agência bancária. 2005. 95 f. Dissertação (Mestrado em Administração) - Programa de PósGraduação em Administração, Universidade Federal do Espírito Santo, Espírito Santo.

OYADOMARI, J. C. T. et al. Influências da remuneração de executivos na congruência de metas. Revista Contemporânea de Contabilidade, Florianópolis, ano 6, v. 1, n. 12, p. 5374, jan./jun. 2009.

PAULINO, M. L. S. Sistemas de controle administrativo no franchising: aliando controle e flexibilidade estratégica. Organizações em contexto, São Paulo, ano 6, n. 12, p. 28-55, jul./dez. 2010.

PIRES, R. G. A informação contábil e a teoria de agência: um estudo da assimetria informacional em companhias abertas, listadas no novo mercado da bovespa. 2008. $120 \mathrm{f}$. Dissertação (Mestrado em Ciências Contábeis e Financeiras) - Programa de Pós-Graduação em Ciências Contábeis e Financeiras, Pontifícia Universidade Católica de São Paulo, São Paulo. 
PIZUTTI, S. T. L. Os efeitos econômico-financeiros dos planos de participação dos empregados nas organizações. 2000. 102 f. Dissertação (Mestrado em Administração) Programa de Pós-Graduação em Administração, Universidade Federal do Rio Grande do Sul, Porto Alegre.

PONTES, B. R. Administração de cargos e salários. São Paulo: Atlas, 2002.

ROSS, S. A. The economic agency theory: the principal's problem. American Economic Review, v. 63, n. 2, p. 134-139, 1973.

SANTOS, J. L. dos; SCHMIDT, P. Contabilidade societária. São Paulo: Atlas, 2011.

TEIXEIRA, A. J. C.; TEIXEIRA, A. M. C.; PIZETA, K. C. Sistemas de incentivos gerenciais e o risco das empresas do estado do espírito santo. Revista de Educação e Pesquisa em Contabilidade, Brasília, v. 5, p. 23-44, set./dez. 2011.

TONANI, R.; SILVA, R. L. M. da. Relação entre a divulgação de pagamentos baseados em ações e os níveis de governança corporativa da BM\&FBovespa. Enfoque: Reflexão

Contábil, Paraná, v. 33, n. 3, p. 51-66, set./dez. 2014.

TRIVIÑOS, A. N. S. Introdução à pesquisa em ciências sociais: a pesquisa qualitativa em educação. São Paulo: Atlas, 1987.

VERGARA, S. C. Projetos e relatórios de pesquisa em administração. 6. ed. São Paulo: Atlas, 2005.

WAGNER III, J. A.; HOLLENBECK, J. R. Comportamento organizacional: criando vantagem competitiva. São Paulo: Saraiva, 2000. 